\title{
Apuntes para la comprensión de la hermenéutica en Heidegger
}

\author{
Paulina Rivero Weber
}

$\mathrm{L}$

as últimas décadas del siglo Xx se encuentran marcadas por una nueva posibilidad no sólo para la filosofía, sino para muchas otras formas del conocimiento: la hermenéutica. Aún es muy pronto para saber si exageraríamos al hablar de una revolución en la historia del pensamiento a partir de la hermenéutica, pero sin lugar a dudas ésta ha transformado a la filosofía. Aunque los orígenes de la hermenéutica podrían muy bien remontarse siglos atrás tanto hacia la cultura judía como a la griega; como corriente del pensamiento contemporáneo encuentra un fuerte impulso en la filosofía de Martin Heidegger, ${ }^{1}$ quien usa este concepto por vez primera en los cursos de Marburgo, alrededor de los años veintes. ${ }^{2}$ A partir de su filosofía, la hermenéutica ha tomado diferentes direcciones, a veces incluso opuestas. Pero hoy por hoy queremos preguntarnos qué significado tiene la hermenéutica para el Heidegger de Ser y tiempo, y cuál es el papel y los alcances que ésta tiene en su obra posterior.

Ya desde sus inicios, como lo han demostrado los estudiosos de la obra heideggeriana previa a Ser y tiempo, ${ }^{3}$ la hermenéutica constituye el núcleo de

${ }^{1}$ Creo que los orígenes de la hermenéutica moderna, tendrían que remontarse más que a Heidegger, al Nietzsche de La genealogía de la moral, esto es, al método genealógico mismo, en la medida en que éste nos lleva a comprender la relación entre perspectiva, interpretación y verdad. Por su parte también Dilthey se refirió explícitamente a la hermenéutica entendiéndola como un método. Veremos cómo Heidegger da el viraje decisivo al considerarla no ya un método, sino un modo de ser humano, esto es: un componente ontológico.

${ }^{2}$ El curso en el cual usa por vez primera el término hermenéutica, y al que se refiere en su conversación con Tezuka Tomio, ha sido traducido al castellano por Jaime Aspiunza, bajo el título Ontología. Hermenéutica de la facticidad (curso del semestre de verano de 1923), Madrid, Alianza, 1999. Al respecto $c f$. Francisco Gil Villegas, Los profetas y el mesías. México, El Colegio de México/FCE, 1997, pp. 455-460.

${ }_{3}^{3}$ Aclaramos tan solo que en el presente escrito no analizamos la obra previa a $\mathrm{El} \mathrm{ser}$ 
su pensamiento. Queda sin embargo una duda: ¿por qué después de esta obra, considerada por muchos como la fundamental de este pensador, no vuelve a aparecer la palabra "hermenéutica"? Es el propio Heidegger quien resalta este hecho en el diálogo con Tezuka Tomio, que tuvo lugar hacia finales de marzo de 1954 , el cual hoy conocemos como "Un diálogo acerca del habla. Entre un japonés y un inquiridor". ${ }^{4} \mathrm{Al}$ no ser del todo clara la significación de la expresión "hermenéutica", el pensador japonés pregunta por ella y por la razón para elegir esta palabra y no otra, así como por el posterior abandono de la misma. Como veremos, a lo largo del mencionado diálogo, Heidegger aclarará muchas de estas cuestiones, pero detengámonos un momento en el inicio del mismo. Heidegger comienza por aceptar que, en efecto, haber abandonado una posición anterior, pero no para cambiarla por otra, sino para continuar en el camino del pensar, lo cual -se nos dice- no necesariamente implica avanzar, sino simplemente permanecer en el camino, y continuar pensando lo que sigue, y también lo que se pensó anteriormente. Si hemos de hacerle caso a lo dicho, la hermenéutica heideggeriana no concluye necesariamente en Ser y tiempo, sino que continuó siendo pensada en la obra posterior. Tal vez -y esta es la tesis que queremos arriesgar aquí- es después de esta primera gran obra que la hermenéutica se pone en marcha, se echa a andar, independientemente de que se mencione o no su nombre. Tratemos de ver primeramente qué significa hermenéutica en Ser y tiempo, para poder ver después qué de ello encontramos en la obra posterior.

Ya desde el parágrafo 7 de la obra se nos dice que la fenomenología de la existencia humana tiene carácter hermenéutico. Pero es realmente en los parágrafos 31 y 32 de El ser y el tiempo en donde Heidegger apuntala las bases de su filosofía hermenéutica, al hacer del "comprender interpretativo" el núcleo central de la existencia humana. ¿En qué consiste este comprender al que se refiere Heidegger? No es una forma de conocimiento entre otras: es el modo de ser más originario o básico que nos remite a una cierta habilidad primaria propia de nuestra existencia, la cual consiste, podríamos decir, en la capacidad de vivir en el mundo cotidianamente estando a la altura de las circunstancias, esto es: de poder tratar diestramente con él. Se trata pues de una

y el tiempo, sino precisamente partimos de este libro para cuestionarnos qué pasa con la hermenéutica en algunas de sus obras posteriores.

${ }^{4}$ Existe traducción al español en De camino al habla. Barcelona, Ediciones del Serbal, 1994. (Colección Odós). Entre los trabajos que destacan para el estudio de este diálogo cabe mencionar, entre otros, el de Friedrich-Wilhelm von Herrmann, Weg und Methode: zur hermeneutischen Phänomenologie des seinsgeschichtlichen Denkens. Existe traducción al inglés en Critical Heidegger. Londres-Nueva York, Routledge, 1996. Otro texto muy recomendable para este mismo respecto es el de Reinhard May, Heidegger's Hidden Sources. East Asian Influences on his Work. Londres, Routledge, 1996. 
comprensión primaria, originaria, que es inherente a nuestras muy variadas formas de existir y de interpretar el mundo. De ahí que Heidegger distinga entre el comprender (Verstehen) y el interpretar (Auslegung). El comprender que desde esta óptica es siempre un comprender afectivo básico, es el fundamento de toda interpretación posible: sólo porque comprendemos, podemos interpretar o pensar en general. La interpretación y su posible explicitación son momentos derivados del comprender básico: "La interpretación -dice Heidegger- se funda existenciariamente en el comprender, en lugar de surgir éste de ella". 5

Vemos, pues, que en lugar de ubicar el conocimiento como algo primario y la comprensión como algo derivado, se nos invita aquí a invertir la fórmula. Lo derivado es la interpretación; lo primario, básico, originario es la comprensión. Comprendemos por el sólo hecho de ser en el mundo: comprendemos porque nuestra forma de ser en el mundo, nuestra estancia en el mundo, consiste en eso: en comprender el mundo en que vivimos de una manera preteórica. La clave está por supuesto en la expresión "ser en el mundo". Completamente cercano en esto a Husserl, Heidegger considera que el mero hecho de ser en el mundo implica tener una cierta intimidad con el mundo. Y por supuesto que no se trata de una reelaboración de la dualidad sujeto-objeto, ya que el individuo y el mundo constituyen un fenómeno dotado de unidad. De ahí que esta propuesta rompa con la manera tradicional de entender los problemas del conocimiento. Durante siglos éstos se enmarcaron de una manera u otra, en la relación entre el sujeto cognoscente y el objeto a conocer, quedando el mundo dividido entre la realidad exterior que se pretende conocer y el sujeto separado de ésta. Para Kant era un "escándalo de la filosofía y de la sana razón humana" el hecho de que aún faltara una prueba contundente de "la existencia de las cosas fuera de nosotros". ${ }^{6}$ Mas el escándalo de la filosofía, responderá Heidegger, "no consiste en que siga faltando hasta ahora esta prueba, sino en que se esperen y se intenten sin cesar pruebas similares". 7 Y es un escándalo porque hemos aceptado desde siempre comenzar por romper, por rasgar en dos la totalidad, para luego buscar la manera de comunicar las dos partes que de entrada hemos separado. ${ }^{8}$

${ }^{5}$ Cf. Martin Heidegger, Sein und Zeit. Tübingen, Max Niemeyer, parágrafo 32, p. 148; M. H., El ser y el tiempo. Trad. de José Gaos. México, FCE, 1971, p. 166; p. 172 de la traducción de Rivera para la Editorial Universitaria de Chile.

${ }^{6}$ Palabras de la Crítica de la razón pura que Heidegger cita en El ser y el tiempo, parágrafo 43 a.

${ }^{7}$ Idem.

${ }^{8} C f$. M. Heidegger, Sein und Zeit, parágrafo 44a, ed. de Max Niemeyer, p. 217; ed. de FCE, pp. 237-238; ed. de la Editorial Universitaria de Chile, p. 237. 
La hermenéutica heideggeriana propone un modelo alternativo al tradicional esquema "sujeto-objeto": considera que ese modelo y su vocabulario no son necesariamente el único punto de arranque posible para la filosofía. Ésta había intentado ofrecer no solamente una definición del conocimiento, sino también un rendir cuentas de cómo aquel que conoce está conectado con lo que se conoce. De ahí que podemos decir que para Heidegger la filosofía tradicional comienza asumiendo una desconexión ontológica básica entre una sustancia mental y una sustancia física exterior, que da lugar a una desconexión entre el sujeto y el objeto, entre la subjetividad y la objetividad. Para Descartes será necesario buscar, posteriormente al establecimiento de esta ruptura, instancias epistemológicas de conexión que no puedan presentar dudas, por ejemplo, el conocimiento de la existencia de un sujeto pensante.

La estrategia heideggeriana implica un giro de 180 grados. Consiste en ver al ser que somos como un ser que se encuentra ya en una conexión ontológica básica con el mundo, la cual garantiza un cierto contacto epistemológico con el mismo. Ser en el mundo implica tener ya una cierta continuidad con él, un cierto contacto, o como ya dijimos, una cierta intimidad con ese mundo en el cual se está. Todo esto sugiere que lo que necesita ser explicado no es la conexión entre el sujeto y el objeto, ya que no existe un sujeto separado de los objetos, sino esa estructura unitaria de "ser en el mundo". Como lo ha visto David Couzens, ${ }^{9}$ lo que en dado caso requiere explicación es la desconexión de esa unidad. Momentos de desconexión obviamente suceden y suceden frecuentemente, por ejemplo, cuando los seres humanos cometemos errores no sólo cognitivos sino prácticos.

Esa conexión o unidad básica entre el ser que somos y el mundo es el resultado de concebir la existencia humana y el mundo como integrantes de un círculo. David Couzens ${ }^{10}$ llega a considerar que Heidegger extiende el tradicional círculo hermenéutico del texto y su lectura hasta el más primordial nivel de un círculo hermenéutico entre la existencia humana y el mundo: porque somos en el mundo, estamos de hecho ya en contacto con él, y por eso nuestra forma de ser en el mundo consiste ya en comprender. Podemos decir esto en palabras del propio Heidegger; la existencia humana "tiene una estructura ontológica circular". ${ }^{11}$ Pero nos preguntamos: ¿este comprender, y esta estructura circular, implican sólo una estructura del ser humano, o implican también contenidos previos de comprensión? Tal vez podríamos

9 David Couzens, "Heidegger and the Hermeneutic Turn", en Charles Guignon, ed., The Cambridge Companion to Heidegger. Cambridge, Universidad de Cambridge, 1993, pp. 170-194.

${ }^{10} \mathrm{Idem}$.

${ }^{11}$ M. Heidegger, Sein und Zeit, parágrafo 32. 
decir que, en tanto se trata de una estructura, existen también contenidos previos de comprensión: pues es por esta capacidad de comprender de manera previa, que toda interpretación y todo conocimiento se mueven dentro de esa estructura previa. En otras palabras, siempre tendremos pre-juicios al conocer, pues la interpretación se mueve dentro de lo comprendido y se alimenta de ello. Este círculo, que el mismo Heidegger llamará en Ser y tiempo no "círculo hermenéutico", sino circulus vitiosus, no es de hecho propuesto como un mero círculo vicioso: verlo así sería no entender de raíz el comprender humano. Quien en los prejuicios de este círculo vea un defecto, no comprende que de hecho en este círculo se alberga la "positiva posibilidad de conocer en la forma más original”. Porque si asumimos la inevitabilidad de estos pre-juicios, podemos lograr de una manera genuina no guiarnos por prejuicios populares, sino acercarnos un poco más a las propias cosas que queremos pensar por cuenta propia. Para ello es necesario que la interpretación comprenda que su primera, constante y última función es evitar que las ocurrencias y los conceptos populares le impongan en ningún caso el tener, el ver y el concebir previos, para desenvolverse todo partiendo de las cosas mismas. ${ }^{12}$

Esto es: de cualquier manera habrá una estructura circular y por lo mismo habrá juicios previos o prejuicios. Pero estos prejuicios pueden venir dictados de conceptos populares no cuestionados, o se puede hacer el esfuerzo de acercarse a las cosas mismas, a los asuntos mismos. Cuando los prejuicios no vienen dictados por las concepciones populares que Heidegger ha llamado el ámbito del "uno" o del "se" - en donde uno actúa como se actúa, o uno piensa como se piensa- es porque se ha hecho el esfuerzo de ir a las cosas mismas desde una perspectiva propia. Hemos pues llegado a un primer sentido de la hermenéutica heideggeriana: la hermenéutica como estructura de comprensión interpretativa, como estructura ontológica del ser que somos. En ese sentido el análisis heideggeriano de la existencia humana como "ser en el mundo" cambia nuestra forma de entender la comprensión, de un fenómeno derivado, a un rasgo central, o más que eso, la comprensión y la interpretación llegan a ser el núcleo mismo de la experiencia humana. ${ }^{13}$

Y, sin embargo, en el mencionado diálogo sobre el lenguaje con Tezuka Tomio, Heidegger dice explícitamente que hermenéutica no quiere decir solamente interpretación, sino que va más profundamente que eso, y nos remite al escuchar y al dar un mensaje. Como lo ha visto Friedrich-Wilhelm von Herrmann, ${ }^{14}$ este diálogo es de suma importancia para el esclarecimiento del significado de la hermenéutica en Heidegger. En el mencionado diálogo ve-

\footnotetext{
${ }^{12}$ Idem.

${ }^{13} C f$. D. Couzens, "Heidegger and the Hermeneutic Turn", en op. cit.

${ }^{14} C f$. F.-W. von Herrmann, op. cit.
} 
mos en efecto que aunque la expresión "hermenéutica" la encuentra por vez primera en sus estudios de teología, viene a él de un lugar más lejano: de Grecia. Para Heidegger, el uso griego de la expresión hermeneuein, va a ser fundamental. Recordemos que el hermenéus griego era el intérprete o traductor. De ahí Hermes, el hermenéus entre los dioses y la humanidad. Pero el hermenéus hace algo más que el mero hecho de interpretar o traducir. Como lo vio Platón en el Ión-diálogo caro a Heidegger- el hermenéus es un ser inspirado, es un ser movido por una fuerza que metafóricamente puede ser comparada con la fuerza de un imán. Éste no sólo atrae un objeto, sino que puede hacer que ese mismo objeto atraiga a otros más; nosotros diríamos: un imán es capaz de imantar a otros objetos. De manera similar, para el Platón del Ión, aquel que es inspirado lo que hace es escuchar y a la vez atraer a otros al transmitir lo que escucha; es a la vez el escucha y el portador de mensajes. Y gracias a ello puede formar-dice Platón- una cadena en la cual unos penden de otros, como sucede con la fuerza del imán. Y este hermeneuein es, tanto para el Platón del Ión como para Heidegger, el poeta, digámoslo mejor con palabras más bellas, que son las de Platón:

[...] es una cosa leve, alada y sagrada el poeta, y no está en condiciones de poetizar antes de que esté endiosado, demente, y no habite ya más en él la inteligencia [...] Pero no es en virtud de una técnica como hacen todas estas cosas $[\ldots]$ sino por una predisposición divina $[\ldots]^{15}$

Tanto para el Platón del Ión como para Heidegger, la labor del hermenéus no nos habla de una actividad racional, sino de una forma pre-teórica de conocimiento. Para Platón el hermenéus escucha a la musa o a los dioses. Para Heidegger, escucha al ser. Y sin embargo -se nos dice-, hemos llegado demasiado tarde para los dioses y demasiado temprano para el ser. Ya no escuchamos más a los dioses, como los antiguos inspirados, y aún no somos capaces de escuchar qué significado tiene el hecho de que algo sea y no simplemente nada, esto es, el significado de la existencia en general. No podemos más pertenecer a religiones teístas después de todas las muertes de dios y de los dioses, y aún no somos capaces de comprender el significado de una religiosidad atea que atienda al llamado del ser. Un ateísmo religioso que no contraponga necesariamente lo sagrado a lo profano, sino que sea capaz de encontrar lo sagrado en aquello que erróneamente se ha considerado lo profano. Y por esta incapacidad de escuchar al ser, tampoco hay lugar alguno para la com-

${ }^{15}$ Platón, Ión. Trad. de Emilio Lledó. Madrid, Gredos, 1993, vol. I, 534b, pp. 243270. 
prensión de lo que significa la existencia. ¿Pero qué es esto de escuchar al ser?, ¿es mística? ¿es un llamado mesiánico? O peor aún, ¿es el llamado de un filósofo que se cree profeta?

Cuando Heidegger habla de atender al llamado del ser se refiere al hecho de que no podemos comprender lo que significa que exista algo -y no simplemente que no exista nada- si no nos detenemos ante ciertas cuestiones fundamentales. Y por no detenernos en ellas, hemos llegado a relacionarnos con el mundo profanamente. Hemos optado por habitar un mundo para el cual nada es sagrado, y por lo mismo todo lo que existe pareciera que está ahí como algo a nuestra disposición para ser explotado, almacenado, consumido y depauperado, como lo hace ver en su análisis de lo Ge-stell. ${ }^{16}$ En un bosquejo muy general del mundo en que vivimos, parafraseando al autor de Introducción a la metafísica, resulta evidente que para nosotros ni la vida humana ni la vida en general es sagrada, el aire tampoco lo es, ni el agua, ni los bosques, ni la tierra. Hemos explotado hasta el último rincón del planeta. El avance tecnológico ha puesto a nuestro alcance de manera instantánea todo acontecimiento, y no por ello vivimos más comunicados, si por comunicación entendemos algo más que la mera información. En cuanto a los intereses que mueven al mundo actual, así como boxeadores y similares son los grandes hombres de un pueblo, de la misma manera el dinero, el éxito personal, u otras deidades menores pueden ocupar fácilmente el sitial vacío de Dios. La desvalorización subsiguiente de la sabiduría nos lleva a un mundo en el cual se tiene por un triunfo digno no la fuerza de la decisión serena y meditada de los sabios, sino las cifras de cientos, miles o millones en asambleas populares: poco importa la sabiduría o la capacidad para gobernar, lo que importa es la habilidad que cada quien tenga para vender su imagen a las mayorías. En pocas palabras, hemos perdido el rumbo. Y según nuestro pensador aún ahora “...como un fantasma que se proyecta más allá de todas estas quimeras, se extenderá la pregunta: ¿para qué?, ¿hacia dónde?, ¿y luego qué?”. ${ }^{17}$ Y en efecto, ¿para qué la existencia?, ¿hacia dónde la llevamos?, ¿cuál es su sentido?

Heidegger no ofrece respuestas concretas a estas preguntas, pero sí nos recuerda la importancia de las mismas, y nos invita a mantenerlas vivas por medio de la escucha y el diálogo, y por lo mismo por medio del silencio y de

${ }^{16}$ Lo Ge-stell, concepto fundamental de la filosofía de Heidegger, se ha traducido como "estructura de emplazamiento" en la medida en que implica emplazar a la naturaleza a dar más de lo que puede por sí, para almacenarle y disponer de ella en el momento en que se considere necesario.

${ }_{17} C f$. M. Heidegger, Einführung in die Metaphysik. Tübingen, Max Niemeyer, 1976, pp. 28-29; M. H., Introducción a la metafísica. Trad. de Ángela Ackermann, Barcelona, Gedisa, p. 42. 
la palabra. Escuchar es ante todo guardar silencio ante el llamado del ser, de la vida, de todo lo que es. Pero no cualquiera guarda silencio; sólo puede guardarlo quien tiene algo que decir, y por lo mismo mutismo y silencio no son equivalentes. Quien enmudece no necesariamente escucha, quien guarda silencio, lo hace para escuchar, no para enmudecer. Al igual que para Heráclito, para el pensador de la Selva Negra todo se armoniza, todo es uno, y los hermenéus serán aquellos que desde sus diferentes perspectivas sean capaces de mantenerse a la escucha y de transmitir lo escuchado por medio de un mensaje.

Para el Heidegger de El origen de la obra de arte, tanto el pensador como el artista en general -ya sea poeta o pintor- puede cumplir con esta función. En estos tiempos de penuria, el hermenéus sigue siendo ante todo aquel que es capaz de prestar oído a un mensaje, al mensaje de qué significa "ser", qué significa que algo "sea". Los poetas, los artistas y los pensadores son los seres que están a la mitad del camino, son los eslabones en la gran cadena del ser. Son los hermenéus que en estos tiempos de penuria, tardíos para los dioses y tempranos para el ser, semejan, en palabras de Hölderlin, "a los sagrados sacerdotes del dios del vino, que de tierra en tierra peregrinan en la noche sagrada". ${ }^{18}$ Ellos cobijan un mensaje a transmitir. Y al hacerlo guardan el sentido de lo sagrado mientras llega el tiempo de una humanidad capaz de comprender el llamado del ser. Pero el "puesto extraordinario" entre todas estas expresiones artísticas lo tiene, según Heidegger, el poeta. Porque la palabra poética es para este pensador no sólo una forma de conocimiento, sino la forma fundadora de todo conocimiento posible. La poesía, como póiesis que es, es obra porque es palabra esencial, y “...cada palabra esencial lucha por sí misma la batalla y decide qué es sagrado o profano, grande o pequeño, atrevido o cobarde, noble o huidizo, señor o esclavo". ${ }^{19}$ En ese sentido la poesía es la forma más elevada, más sublime de hablar; la poesía es el habla de la cual deriva toda otra forma posible de hablar. La poesía funda, y por lo mismo consagra y glorifica. Y aquí para Heidegger "consagrar significa sacralizar" en el sentido de que por medio del poema, o de la obra de arte, "lo sagrado se abre como sagrado y el dios es llamado a ocupar la apertura de su presencia". ${ }^{20}$

Existe pues una relación entre el arte -en particular la poesía- y lo sagrado. La poesía no es una forma de hablar derivada a la cual llega un pueblo que

${ }^{18}$ Cf. Hölderlin, "Pan y vino", en Las grandes elegías. Ed. bilingüe. Barcelona, Ediciones 29, 1977, p. 161. Las ideas expuestas en este poema son retomadas por Heidegger en más de una ocasión.

${ }^{19}$ M. Heidegger, Der Ursprung des Kunstwekes. Fráncfort, Vittorio Klostermann, p. 29; M. H. Arte y poesía. Trad. de Samuel Ramos. México, FCE, p. 73; p. 36 de la traducción de Cortés y Leyte para Alianza Editorial.

${ }^{20}$ Idem. 
ha accedido a una etapa superior en el camino de su culturización. No es tampoco una manera adornada o agradable de decir las cosas. Hacer poesía es situarse en una experiencia originaria frente a la vida y dar nombre a las cosas, nombrar, y no simplemente repetir. Porque dar nombre no es repetir, sino fundar. Y al fundar, nuevamente podemos decirlo, delimitamos lo sagrado y lo profano, lo grande y lo pequeño, lo que es y lo que no es.

En esta relación hermenéutica se encuentra por un lado la disposición del poeta, y por el otro la del receptor. El arte, particularmente la poesía, ofrece una "impulsión", que nos lleva a salir de la mirada cotidiana para reinterpretar de una manera diferente y original lo que anteriormente habíamos mirado sin ver. El arte puede ayudar, puede provocar una experiencia "originaria", que nos muestre, nos desoculte algo aún no visto. Y también el pensamiento reflexivo puede impulsionarnos a una experiencia de este tipo. Así, en Construir, habitar, pensar, es la reflexión sobre un puente -y no la contemplación de un puente de Monet- lo que lleva a Heidegger a encontrar el sentido de lo sagrado. O, en la conferencia sobre $L a \cos a$, es una sencilla y cotidiana jarra de agua, y no una representación artística de ella, la que le lleva a pensar en la Cuaternidad, el sitio en donde se reúnen cielo y tierra, mortales y divinos.

Existe pues una impulsión que nos lleva en efecto a comprender lo que la cosa es; nos conduce a un mirar hermenéutico en el cual somos capaces de ver lo que otros no pueden, o lo que nosotros mismos en circunstancias habituales y cotidianas no podemos ver. El arte es sólo un camino posible, el pensar reflexivo y meditativo es otro más. Los caminos del pensar heideggeriano son en ese sentido un ejemplo y una puesta en marcha de una nueva forma de filosofar que se ha llamado "hermenéutica", que conlleva una nueva concepción de la verdad que ha revolucionado la historia del pensamiento occidental. Para esta filosofía más que "verdades absolutas" hay interpretaciones parciales y fragmentadas, que no por ser tales pierden su carácter auténtico y vinculante. Podríamos decir que la verdad, tanto para Heidegger como para Aristóteles "nadie puede alcanzarla dignamente, y nadie yerra por completo". ${ }^{21}$ Y por supuesto, en la medida en que comprendamos que no hay verdades absolutas, seremos más capaces de guardar silencio y escuchar las verdades de los otros. Y seremos por lo mismo más capaces de comprender que las diferentes perspectivas de la verdad enriquecen la perspectiva propia: parafraseando a la poeta Emily Dickinson, mientras más multipliquemos los muelles, mayor será nuestra comprensión del mar. ${ }^{22}$

${ }^{21}$ Aristóteles, Metafísica. Ed. trilingüe. Madrid, Gredos, 1990, libro II (A elatton) 993b 30, pp. 84-85.

${ }^{22}$ En el original se lee "multiplicar los muelles no disminuye el mar". $C f$. Emily Dickinson, Collected Poems. Filadelfia, Running Press, 1991. 